\title{
Factors Affecting Students' Satisfaction Regarding Semester System: Evidence from Pakistani Universities
}

\author{
Iqra Sardar ${ }^{1}$, Zeeshan Maqsood ${ }^{2}$, Sana Jawad ${ }^{3}$, Rahila Akhtar3, Humaira Latif ${ }^{3}$
}

1 Lecturer, Department of Statistics, University of Haripur, Pakistan

2 Lecturer, Department of Statistics, University of Sialkot, Pakistan

3 Teaching Assistant, Department of Quantitative Methods, University of Management and Technology, Lahore, Pakistan

* Corresponding Author (zshanstatistician@gmail.com)

Received:O2 Nov, 2019

Revised: 12 Dec, 2019

Accepted: 27 Dec, 2019

Published: 28 Jan, 2020

How to cite this paper: Sardar, I., Maqsood, Z., Jawad, S., Akthar, R., Latif, H. (2019). Factors affecting students'satisfaction regarding semester system: Evidence from Pakistani Universities. Quest Journal of Management and Social Sciences, 1(2), 192-201.

Copyright (C) 2019 by authors and Quest Journal of Management and Social Sciences

This work is licensed under a Creative Commons Attribution-NonCommercial-NoDerivatives 4.0 International License.

https://creativecommons.org/licenses/by-nc-nd/4.0/

\begin{abstract}
Background: Knowledge of students is more important as compared to their position, marks, and G.P.A. Learning for students performs a vital role as it helps them achieve what they desire in their educational profession. Semester system is based on a six-month duration, examination at the end of each semester.

Objective: This study attempts to find out satisfaction levels of students regarding the semester system in colleges. The study explores various factors like the role of teachers, types of courses, time duration, the medium of learning, management system, college environment, group work factors, all of which have significant impact on satisfaction levels of the students.
\end{abstract}

Methods: BS Students were taken as target population to take the research sample. Primary data were collected with the help of questionnaire and then analyzed by using SPSS software.

Results: Results show that semester system is perceived to be a most effective way of effectual learning; however, the satisfaction level of students can be enhanced by cooperative efforts of teachers and students.

Conclusions and Recommendation: Although there are many factors elaborated in the study that can efficiently enhance student's satisfaction, the teacher's efforts and behavior are the main factors which are directly related to the student's satisfaction.

Keywords: Student Satisfaction Factors, Academic regulations, Higher Education, semester system

Originality: This is the original work of author and not submitted for publishing in other publications

Paper Type: Research paper

JEL Classification: I21, I22, I25 


\section{Introduction}

The learning procedure of students is called education. Fulfillment of needs, purpose, expectations is called satisfaction. Knowledge of students is more important as compared to their position, marks, and G.P.A. Learning for students performs a vital role as it helps them achieve what they desire in their educational profession. There are three aspects included in student satisfaction: teaching methods, course administration, and teaching staff. Annual examination system is the system which showed one final examination at the end of one-year period. Semester system is based on a six-month duration, examination at the end of each semester. In this system, one-year period consists of two semesters. Before this study, student satisfaction has never been measured as an issue of importance by educational experts nor considered a problem of the present by higher educational institutes. Shirai et al. (2013) focused on the satisfaction conception in the framework of higher education and because of that concept, our objective is now to create some assumptions about the satisfaction of the graduates. When a student graduates from a university, $\mathrm{s} /$ he would like to have some skills that are required for jobs. Some of these skills are knowledge, communication, problem-solving, critical thinking, leadership, etc. These skills will doubtlessly contribute to his/her career progress and satisfaction with a career in the future. Kotler (2011) highlighted that when actual outcome matches the observed ones then the emotion of exact gladness is handled and this, they call satisfaction. In the background of student satisfaction, they described that students imagine something from their institution and if their hopes match with the real condition of the college then they get satisfied and the results are creative.

As a good source of revenue, Abbasi et al. (2011) gives details about factors which affect satisfaction and dissatisfaction in Bahauddin Zakariya University of Pakistan on the basis of a few factors, which are: teachers' behavior, teachers' feedback, response of official staff, cafeteria environment, facility of pick up and drop off, availability of laboratories etc. The results of the study points out that the students are dissatisfied with the facilities provided by the universities of Pakistan. Bidani (2010) studied that in an annual system, students studying at the time of exam feel a lot of burden of the syllabus on their shoulders, whereas in a semester system the burden of the syllabus is less. In the same way, surprise tests and quizzes that are taken in the semester system help students to achieve good marks in their final exams because it prepares students before the examination time. The increase in time for assessments, along with the hardwork of students, helps them to develop their assignments, test, and other reports, which in turn help students to correct their errors. Herman et al. (2009) elaborated that communication between teacher and student is also the main factor to enhance student's satisfaction in the semester system. Kotler and Keller, as cited by Ali (2004) pointed out that for the usefulness of the system, satisfaction is required.

Student's satisfaction is highly imperious because if they are fully satisfied with the facilities provided by the colleges, their positive responses will encourage more students to join the colleges. Kotler and Keller (2004) also stated that if the students are satisfied then the end results will be automatically excellent. Ali (2004) mentioned that Institute of Management Studies (colleges of Peshawar, Pakistan) also faces dissatisfaction of students and the main reason is that the teachers' behavior is intolerant, they always come late to class and 
never give good feedback to students' assignments and if the students ask for feedback, they always demotivate them by giving bad responses. In this sense, this study aims to identify factors affecting students' satisfaction regarding semester system in Pakistan. The understanding will help policy makers and educationalists formulate strategies and make plans for better education along with the contribution of future researchers.

The organization of the paper is as follows: Section 2 represents the literature review on value chains; section 3 discusses materials and methods with data collection techniques, study area; section 4 covers the result and discussion; and section 5 presents conclusion and recommendation.

\section{Review of Literature}

Semester system provides a chance for students to learn more through the presentations, mid-term examinations, group discussions and submission of assignments etc. with regular bases (Abro, 2014). According to Long et al. (2014), competencies such as knowledge on the subject, clarity of presentation, interaction with students, teaching creativity, clarifying learning outcome, class activity, and lecture notes are significantly related to student satisfaction. They positively show that lecturer's knowledge of subject contributes most to students' satisfaction.

Sabir et al. (2013) had divided the education systems of the colleges into two types. They are the semester system and annual system. Semester system divides the educational year into two terms. It has been known to be more innovative, correct and cooperative than the annual system. It examines the students' presentation every six months. Aslam et al. (2012) analyzed the factors affecting student's satisfaction regarding the semester system in University of Pakistan. While they are investigating factors elaborated in the current study that can efficiently enhance student's satisfaction, the teacher's efforts and behavior are the main factors which are directly related to the student's satisfaction. Abbasi (2011) had measured the level of student satisfaction with current facilities existing in Pakistani colleges. The consideration and comparison of possible differences in terms of the level of satisfaction through gender and various programs/disciplines formulate key objectives. Overall, satisfaction level is shockingly low and results show dissatisfaction of college students on educational services presented by Pakistani colleges.

Bidani (2010) defined its own experts and ploys yet the excellence of learning takes place on the part of students' as one cannot discharge the burden. The greatest benefit of learning under semester system in colleges is that each student remains knowledgeable about his production and development through nonstop opinions from the colleges and the students are regularly tested so there is no way of taking study as a secondary priority. Kotler (2009) described satisfaction as 'a person's feeling of pleasure or disappointment, which resulted from comparing a products perceived performance or outcome against his/her expectations'. It means if the presentation matches the probability, the students will be satisfied. In the background of higher education, the problem of satisfaction is whatever students believe from their educational institution, in fact, the whole thing that makes them suitable to become a useful and effective person in their life. 
Webster-Stratton (2008) categorized insufficient basic characteristics that employers generally seek from a college graduate. These include knowledge, intellectual abilities, and the ability to work in current administrations, interactive skills, and communication skills. Kara \& DeShields (2004) described practical data and theoretical model to prove that students' college experience is positively related to their satisfaction and purposes to stay at college or university. Carey et al. (2002) argued that satisfaction truly manages problems of students' awareness and abilities during their educational years. Earlier, Clifford (1997) presented students satisfaction and maintenance model. According to this model, ability, guiding staff, classroom abilities and general nature of students apply to the knowledge acquired in the college and consequently measure key satisfaction and maintenance mechanisms. Pike (1994) and Pace (1979) suggested graduates' satisfaction as an important mechanism for judging the properties of educational organizations.

\section{Research Methods}

The study applies cross-sectional descriptive and explanatory research design. In order to explore the issues of students' satisfaction about semester system, researchers designed questionnaires to collect primary data. For assessing the collected data SPSS software was used and simple means, standard deviation and frequencies were taken into account that reflected each variable under study.

\section{Data Analysis and Result}

The sample of the questionnaire revealed results for nine major factors. As Table 1 highligts the efficiency of semester system schedule management, the result of mean depicts that approximately $38.4 \%$ students agree that results are declared on time in semester system. They think that, in semester system, frequent examination is arranged to provide quick self-evaluation to students through proper results on time. Majority of the respondents including 27.7\% students were strongly unsatisfied with this statement, few of the students collaboratively thought that, if the results are not declared on time, they get frustrated and could not remain motivated for next exam. "However, $33.9 \%$ of the individuals were found to be neutral about the declaration of results on time. Majority of students $62.4 \%$ agreed with the statement "there is enough time for learning in semester system". A student stated that "a semester of four months or six months obviously seems to be having more time constraints. But in fact, the course is designed in a manner that it creates enough space for a student to perform and learn ineffectual manner". Approximately $6.6 \%$ respondents mentioned their dissatisfaction with the statement, however, $30.6 \%$ of the respondents were neutral about the research question that whether the semester system gave them enough time for learning or not. A majority of students $64.6 \%$ were positively satisfied with the sufficiency of time for assignments and has agreed that 'time duration attended by the instructor for the preparation of assignments is sufficient for academic learning”. About a quarter of respondents i.e., 23.3\% were neutral about the above-mentioned statement and $11.8 \%$ were dissatisfied. On exploring the factor i.e., in time completion of the semester, the result of mean depicted that majority of students $60.5 \%$ agreed that the department successfully completed the semester 
in time. The main reason for this delay is weak management policies and uncertain semester breaks. Approximately, 25.8 \% of the students disagreed with the statement that "instructor always covers the syllabus well in time during the semester". However, $13.3 \%$ students were neutral in this regard and suggested that students were given less opportunity to implement the coursework.

Table 4.1 Effective Semester Schedule Management

\begin{tabular}{|l|r|r|r|r|r|}
\hline Factor & Mean & Standard deviation & Unsatisfied & Neutral & Satisfied \\
\hline Declaration of results in time & 1.89 & 0.807 & $75(27.7 \%)$ & $92(33.9 \%)$ & $104(38.4 \%)$ \\
\hline Better time for learning & 1.44 & 0.617 & $(18)(6.6 \%)$ & $83(30.6 \%)$ & $169(62.4 \%)$ \\
\hline Sufficient time duration 4 months & 1.62 & 0.721 & $38(14.0 \%)$ & $91(33.6 \%)$ & $141(52.0 \%)$ \\
\hline Sufficient time period for assignments & 1.47 & 0.699 & $32(11.8 \%)$ & $63(23.3 \%)$ & $175(64.6 \%)$ \\
\hline Course completion with in time & 1.53 & 0.720 & $36(13.3 \%)$ & $70(25.8 \%)$ & $164(60.5 \%)$ \\
\hline
\end{tabular}

As shown in Table 2, about 73.8\% students strongly agreed that group work was properly allocated between the group members who helped the students in the group to manage the workload positively. However, 15.5\% respondents remained neutral in this regard. Moreover, about $10.7 \%$ disagreed with the statement "Group works during the class helped students share their difficulties with peers". Because students faced the time constraints and some had to do double tasking by working for their peers. A student argued that "in a group, every individual tried to impose his/her opinion on the other because it's a reality that we value our ways of thinking and performance over the ideas of other". Therefore, the task was not shared among the group members freely, hence the difficulty increased"

Table 2: Group work

\begin{tabular}{|c|r|r|r|c|c|}
\hline \multicolumn{1}{|c|}{ Factor } & Mean & Standard deviation & Unsatisfied & Neutral & Satisfied \\
\hline Groups study helps in better learning & 1.37 & 0.670 & $29(10.7 \%)$ & $42(15.5 \%)$ & $200(73.8 \%)$ \\
\hline Group work helps to share difficulties & 1.34 & 0.606 & $919(7.0 \%)$ & $54(19.9 \%)$ & $197(72.7 \%)$ \\
\hline
\end{tabular}

Information in Table 3 revealed that a majority of students i.e., 60.1\% were positive about the overall progress of students and agreed that the "semester system helps them in improving the overall progress of students". About $6.3 \%$ of students felt that semester system did not help them improve the overall progress of students. These unsatisfied students commented that teaching styles should be formulated from the students' perspectives, if the style adopted by a teacher was ambiguous, it would cause difficulties in understanding and memorizing. Approximately $60.9 \%$ of the respondents were satisfied with the statement that "syllabus is very helpful in the acquisition of specific skills". One of the students mentioned that "if you will be professional in 30.3\% of your field then it's a success for you, otherwise, no one will give you any credit!" While $8.9 \%$ of the respondents, remained neutral. And 18.3\% of the students disagreed with the statement and suggested that the semester system did not promote skill development. On exploring another major feature of individual learning i.e., "personality development" $10 \%$ were dissatisfied while $28 \%$ of the respondents remained 
neutral. About $62 \%$ of the respondents were satisfied with the statement, "semester system is useful for overall personality development”.

Table 3: Individual Learning

\begin{tabular}{|l|r|r|r|r|r|}
\hline Factors & Mean & $\begin{array}{r}\text { Standard } \\
\text { deviation }\end{array}$ & Unsatisfied & Neutral & Satisfied \\
\hline Improvement in overall progress & 1.46 & 0.613 & $17(6.3 \%)$ & $91(33.6 \%)$ & $163(60.1 \%)$ \\
\hline Sense of accomplishment & 1.57 & 0.597 & $15(5.5 \%)$ & $125(46.1 \%)$ & $131(48.3 \%)$ \\
\hline Skills development & 1.48 & 0.654 & $24(8.9 \%)$ & $82(30.3 \%)$ & $165(60.9 \%)$ \\
\hline Personality development & 1.48 & 0.671 & $27(10 \%)$ & $76(28 \%)$ & $168(62 \%)$ \\
\hline $\begin{array}{l}\text { Involvement of students in co-curricular } \\
\text { activities }\end{array}$ & 1.78 & 0.752 & $53(19.6 \%)$ & $105(38.7 \%)$ & $113(41.7 \%)$ \\
\hline
\end{tabular}

As shown in Table 4 that about $74.9 \%$ of the respondents were strongly satisfied with the statement that "students understand and satisfied with GPA System". They emphasized that they comprehended this system and aligned their efforts accordingly. About 48.7\% of the respondents were satisfied with the statement "evaluation through GPA System is a true reflection of achievement". A student argued, "Evaluation is recognized as a comprehensive, systematic, and purposeful process that is an integral part of teaching and learning, and it is better done through the GPA system". About 40.6\% of the respondents were satisfied with the statement, "minimum GPA required to remain to enroll in a semester is necessary for quality of education". Respondents said, "Constraints of GPA is good because it helps students to maintain their minimum requirement of GPA as this saves them from the problem of discontinuity the program i.e., dropouts". On the other hand, $11.4 \%$ of the respondents were unsatisfied while $48 \%$ remained neutral with regard to this question. About $66.4 \%$ were satisfied with the statement "marks of sessions are always adjusted according to predefined marks allocation criteria”. However, $14.8 \%$ disagreed with the statement. They cited the reason, "marks allocation is not predefined or teachers do not follow predetermined criteria of marking". With this question, $18.8 \%$ took their nuetra position.

Table 4: Grading system

\begin{tabular}{|l|r|r|r|r|r|}
\hline Factor & Mean & $\begin{array}{r}\text { Standard } \\
\text { deviation }\end{array}$ & Unsatisfied & Neutral & Satisfied \\
\hline GPA System & 1.33 & 0.614 & $21(97.7 \%)$ & $46(17 \%)$ & $203(74.9 \%)$ \\
\hline Evaluation of Achievement through GPA & 1.62 & 0.667 & $28(10.3 \%)$ & $111(41 \%)$ & $132(48.7 \%)$ \\
\hline Minimum GPA constrain & 1.71 & 0.661 & $31(11.4 \%)$ & $130(48 \%)$ & $110(40.6 \%)$ \\
\hline Sessional Marks & 1.48 & 0.740 & $40(14.8 \%)$ & $51(18.8 \%)$ & $180(66.4 \%)$ \\
\hline
\end{tabular}

On exploring the value of semester system education in practical life, approximately $67.2 \%$ of the students agreed with the statement, "Taught Courses will be useful in professional life" as shown in Table 4. The research findings revealed that students were very concerned about what was being taught to them and the practical implementation of its core knowledge. However, $12.2 \%$ of the respondents disagreed with the statement. $20.7 \%$ of students were neutral in this regard and suggested that practicality should be preferred over bookish knowledge and other formal methods of education so that a student could equip himself/herself with the best practices in the marketplace and could be able to reflect professionalism. 
Table 5: Curriculum Management

\begin{tabular}{|l|r|r|r|r|r|}
\hline Factor & Mean & $\begin{array}{r}\text { Standard } \\
\text { deviation }\end{array}$ & Unsatisfied & Neutral & Satisfied \\
\hline Course helps in professional life & 1.45 & 0.702 & $33(12.2 \%)$ & $56(20.7 \%)$ & $182(67.2 \%)$ \\
\hline Social courses to cover social norms & 1.71 & 0.710 & $40(14.8 \%)$ & $112(41.3 \%)$ & $119(43.9 \%)$ \\
\hline Courses helps to enhance knowledge & 1.31 & 0.582 & $17(6.3 \%)$ & $49(18.1 \%)$ & $205(75.6 \%)$ \\
\hline Courses helps in practical field work & 1.55 & 0.758 & $44(16.2 \%)$ & $61(22.5 \%)$ & $166(61.3 \%)$ \\
\hline
\end{tabular}

It was revealed through the mean outcome that despite the study burden and time constraints; the semester system was perceived to be the most moderate system of education. As shown in Table 6, a significant percentage of respondents i.e., 41\% agreed that "Semester system helps students to reduce the burden on students as compared to the annual system". In addition to that, $36.2 \%$ of students strongly expressed that the course outline was properly distributed between the mid and final term examinations that helped a student to manage the workload effectively. As compared to the semester system, in annual system students need to complete the course in a complete year which made it difficult for a student to manage at the end of the year in the final examination.

Table 6: Reduced Burdens

\begin{tabular}{|l|r|r|l|l|r|}
\hline Factor & Mean & Standard deviation & Unsatisfied & Neutral & Satisfied \\
\hline Reduction of burden & 1.73 & 0.688 & $37(13.7 \%)$ & $123(45.4 \%)$ & $111(41.0 \%)$ \\
\hline Division of Burden & 1.81 & 0.705 & $46(17.0 \%)$ & $127(46.9 \%)$ & $98(36.2 \%)$ \\
\hline
\end{tabular}

As shown in Table 7, with regard to constructive feedback, 69\% respondents were satisfied with the statement, "Students get sufficient guidance from teachers while preparing assignments". These students said that they got an appointment with the teachers easily and the educational technology such as the internet revived the ways of student-teacher interaction. However, 8.9\% students have disagreed in this regard. On exploring the value of constructive feedback it was found that the process of evaluation and assessment of a student was highly imperative for the consistent growth of a student's academic career. The majority of candidates i.e., $43.9 \%$ stressed that continuous constructive feedback was the best part of a semester system and agreed with the statement, "Comments given by the teachers on the assignment are very helpful for further improvement during semester". On the other hand, $45 \%$ gave a neutral response and $10.9 \%$ of students claimed that the feedback depended on the mood of the teachers, many teachers created an atmosphere of comparison and competition when they provided feedback, which definitely decreased student's morale. Only $17 \%$ of the students disagreed, "in semester system lecture is delivered in an interesting way." These students stated that they were mostly taught through PPT presentations that hardly created any interests in the lecture. About 29.2\% of the students were found to be neutral in this regard; however, $53.9 \%$ of students who were satisfied listed the techniques for the enhancement of interest in the lectures.

On exploring the issue of availability of information for the assignments, 70\% students were exposed to be in the favor of the statement "The material for preparation of assignment is easily available with sufficient teacher's guidance on searched material”, because they were 
of the view that the knowledge nowadays was no more a property of teachers. Internet, search engines and electronic journals were in easy access to a student. Hence, the students can conveniently explore the issue. However, teachers were also needed guidance in order to understand the knowledge available on open internet resources.

Table 7: Constructive Feedback

\begin{tabular}{|l|r|r|r|r|r|}
\hline Factor & Mean & $\begin{array}{r}\text { Standard } \\
\text { deviation }\end{array}$ & Unsatisfied & Neutral & Satisfied \\
\hline Teachers support & 1.40 & 0.647 & $24(8.9 \%)$ & $60(22.0 \%)$ & $187(69 \%)$ \\
\hline Constructive Feedback & 1.67 & 0.662 & $29(10.7 \%)$ & $122(45.0 \%)$ & $119(43.9 \%)$ \\
\hline $\begin{array}{l}\text { Availability of data for assignment and } \\
\text { teacher's guidance }\end{array}$ & 1.63 & 0.758 & $46(17.0 \%)$ & $79(29.2 \%)$ & $146(53.9 \%)$ \\
\hline
\end{tabular}

Computer technology is basically working as an interactive tool and a catalyst to modernize the obsolete education system and to train the students for the modern technological change. As shown in Table 8, the mean indicated that almost $67.2 \%$ of the students perceived that they understood the medium of instruction and the way in which lectures were delivered. On the other hand, 4.4\% disagreed, "Medium of instruction is understandable. A majority of students i.e., $52.8 \%$ were positive about the teaching methodology and agreed, "teaching style in semester system motivates students towards effective learning". Almost all of the students thought that, in the semester system, a student is given more autonomy towards learning by teachers. Respondents also mentioned that the style of teaching is selected according to the nature of the topic; hence the personality and moods of teachers should not be blamed in this regard. When the issue of knowledge and understanding was explored, the mean showed that students agreed with the statement. Almost two-third i.e., $69.7 \%$ of the students agreed that "teaching in semester system gives sufficient knowledge and practical understanding of the subject”. However, 8.5\% of individuals did not agree with the statement because they thought that teaching style needed improvement. Many times it was the teaching method that created stress among students; they felt pressurized due to burden and insufficient teaching methods/resources. Respondents mentioned that several times the course was left the mid-way and teachers were replaced. On the other hand, students also showed concerns that very often the syllabus was left incomplete because of unmatched teaching styles of some teachers and the objectives of the course were not achieved as mentioned in the course outline in beginning of the semester.

Table 8: Students' Motivation by Teaching Methodology and Resources

\begin{tabular}{|l|r|r|r|r|r|}
\hline Factor & Mean & Standard deviation & Unsatisfied & Neutral & Satisfied \\
\hline Understandable medium of instruction & 1.37 & 0.569 & $12(4.4 \%)$ & $77(28.4 \%)$ & $182(67.2 \%)$ \\
\hline Motivation through Teaching Methodology & 1.60 & 0.702 & $34(12.5 \%)$ & $94(34.7 \%)$ & $143(52.8 \%)$ \\
\hline $\begin{array}{l}\text { Knowledge and Understanding through } \\
\text { Teaching }\end{array}$ & 1.39 & 0.639 & $23(8.5 \%)$ & $59(21.8 \%)$ & $189(69.7 \%)$ \\
\hline
\end{tabular}

\section{Conclusion and Recommendations}

This research investigated students' satisfaction regarding the semester system in a college. The key focus of this research was to find out the "factors affecting students' satisfaction regarding the semester system in a college". Based on the changing marketplace for this in- 
stitution, college administrators and researchers need to focus their considerations on students' satisfaction strategies to achieve organizational objectives.

The research showed that students were more satisfied with the semester system than the annual system. On the prevailing ineffectiveness of the annual system, this research was carried out to find out the comparative differences between the annual and semester systems to ensure the effectiveness of learning process for academic excellence in this institute. Results showed that students learn more through semester system as compared to the annual system due to the flexibility in the environment. The study revealed that the students feel less burden of syllabus in semester system compared to the annual system. Semester system allows practical assignments, presentations, and quiz system that prepare the students for the semester end examinations and test system resolves ambiguities of students regarding their course contents.

Different factors studied in this research and results showed that the grade division in the GPA system enhances the level of satisfaction in students. The study also indicates the effective way of learning process that satisfies the students because with course outline students judge the teaching pattern of teachers. The research study shows that other factors like the division of course among various semesters, group assignments, devising exercises during semesters, personality development of students are major factors for students' motivation. The interaction between teachers and students is also effective because effective communication brings better outcomes. However, some of the discouraging factors, according to present research, are weak semester administration by the management, lack of teachers' training and misuse of teachers' authority.

Most students are satisfied with the semester system but some changes in this system are most important to the satisfaction of students. In this system, quantity is improving but the qualities are not. It is recommended that in this system quantity is increasing through subjects but the qualities are not increasing through concepts and skills development. To increase the quality of education we have to train the teachers and minimize the workload or quantity of students.

Favoritism should be removed in this system. The management system of the department should be improved, and teaching methodology should also improve. Teachers should have to use multimedia during their lectures because students understand things much better through a multimedia presentation. Teachers can enhance education by giving practical examples. Sufficient time for the semester is to be allotted for effective learning. So, there must be group work and availability of sources and time to learn and work properly. Teaching methodology should be improved to enhance the interest of students in studies. Teachers should properly follow course outlines and complete the full coursework.

As a matter of fact, student satisfaction has never been considered as an issue of importance by educational authorities nor regarded as a matter of survival by higher education institutions. This is evident from the fact that the impact of educational services provided by colleges on the satisfaction level of their students has largely been an area that remains unknown. Therefore, this study may yield important aspects related to the semester system and the ways in which it can be modified and refined.

\section{Conflict of Interest}

The authors declared that they have no conflict of interests. 


\section{References}

Abbasi, M. N., Malik, A., Chaudhry, I. S., \&Imdadullah, M. (2011). A study on student satisfaction in Pakistani universities: The case of BahauddinZakariya University, Pakistan. Asian Social Science, $7(7), 209$.

Abro, S. (2014). Critical Analysis of semester and annual system. Chandka academic forum.

Ali, I. (2001). The Degree of Student Satisfaction in Higher Education: A Comparative Study between a Public and Private University. Peshawar: Institute of Management Studies.

Aslam, H. D., Younis, A., Sheik, A. A., Maher, M. Z. A., \& Abbasi, Z. A. (2012). Analyzing factors affecting students' satisfaction regarding semester system in universities of Pakistan. Journal of American Science, 8(10), 163-170.

Bidani, S. (2010). Semester System and Privatization of Education: Boon or Bane. (2010). Retrieved from http://www.youthkiawaaz.com/2010/06/semester-systemand-privatization-of-education-boon-or-bane/

Carey, K., Cambiano, R. L., \& De Vore, J. B. (2002). Student to Faculty Satisfaction at a Midwestern University in the United States. HERDSA, 93-97. [Online] Available: www.ecu.edu.au/conferences/herdsa/main/papers/ref/pdf/Carey.pdf.

Clifford, K. O. (1997). College students' perceptions of academic integrity and campus climate at small colleges. The University of Iowa, USA.

Herman, K. C., Reinke, W. M., Parkin, J., Traylor, K. B., \& Agarwal, G. (2009). Childhood depression: Rethinking the role of the school. Psychology in the Schools, 46(5), 433-446.

Kara, A., \& DeShields, O. W. (2004). Business student satisfaction, intentions and retention in higher education: An empirical investigation. Marketing Educator Quarterly, 3(1), 1-25.

Kotler, P. (2009). Marketing management: A south Asian perspective. Pearson Education India.

Kotler, P. (2011). Philip Kotler's contributions to marketing theory and practice. In Review of Marketing Research: Special Issue-Marketing Legends (pp. 87-120). Emerald Group Publishing Limited.

Kotler, P., \& Keller, K. L. (2004). Fundamentals of Marketing Management. Translated by Ali Parsaeian, Termeh Publication.

Long, C. S., Ibrahim, Z., \& Kowang, T. O. (2014). An analysis on the relationship between lecturers' competencies and students' satisfaction. International Education Studies, 7(1), 37-46.

Pace, C. R. (1979). Measuring the Outcomes of College. San Francisco: Jossey-Bass.

Pike, G. R. (1994). The relationship between alumni satisfaction and work experiences. Research in Higher Education, 35(1), 105-123.

Sabir, R. I., Ahmad, W., Ashraf, R. U., \& Ahmad, N. (2013). Factors affecting university and course choice: A comparison of undergraduate engineering and business students in Central Punjab, Pakistan. Journal of Basic and Applied Scientific Research, 3(10), 298-305.

Shirai, T., Shimomura, H., Kawasaki, T., Adachi, T., \& Wakamatsu, Y. (2013). Job search motivation of part-time or unemployed Japanese college graduates. International Journal for Educational and Vocational Guidance, 13(2), 95-114.

Sunder, P. (2018). Attitude of the stakeholders of education towards semester system. National Journal of Multidisciplinary Research and Development. 3(1). 411- 413.

Webster-Stratton, C., Jamila Reid, M., \& Stoolmiller, M. (2008). Preventing conduct problems and improving school readiness: evaluation of the incredible years teacher and child training programs in highrisk- schools. Journal of child psychology and psychiatry, 49(5), 471-488. 